Check for updates

1 King's College London.

2 Western Sydney University

Twitter: @amshep95@benhanckel Cite this as: BMJ 2021;375:n2858 http://dx.doi.org/10.1136/bmj.n2858 Published: 19 November 2021

\section{Ensuring equal access to care for all transgender people}

\section{As healthcare providers revise their approaches to transgender health, they also need to rethink their approaches to gender in healthcare consultations, say Adam Shepherd and Benjamin Hanckel}

\section{Adam Shepherd, ${ }^{1}$ Benjamin Hanckel ${ }^{2}$}

There have been growing efforts to make healthcare inclusive of all trans people. Inclusive care is often measured through care provider practices, often resulting in visible LGBTIQ+pamphlets, rainbow flags, posters, and pronoun badges to promote inclusivity.

While such changes are important, they do not address some of the more ingrained problems with current healthcare systems, such as unhelpful categorisations of gender on medical records.

These designate a patient as either "male" or "female," which presumes that people have particular anatomies and physiologies based on these categories, and does not provide trans people with the support they require.

The structure of medical records was noted as a concern in the Royal College of General Practitioner's 2019 statement on trans care. ${ }^{1}$ They argued that a rigid system of medical records that does not account for all people can have implications for access to healthcare, for example with screening programmes. ${ }^{2}$

When these assumptions about gender fail to reflect the realities of trans individuals and their bodies, participation in healthcare becomes more difficult for them. Transgender people's experiences are rendered invisible as they have to fit themselves into pre-existing healthcare structures, which do not recognise or account for their needs.

Our analysis of healthcare guidance documents related to transitioning used by NHS England over the last 12 years points to these limitations. ${ }^{3}$ Examining these documents, alongside interviews with trans people about their lived experiences of transitioning, we found not only that healthcare guidance often imagined transition in particular ways, but that participants had to confront these limitations in their everyday lives.

Take Jack for example, a trans man who sought to update his information at his GP practice. Realising that they "would have to generate a new NHS number" for him, Jack decided against this due to the perceived ramifications it would have for his health record. As he said, "What is the point [if I will]...lose all of my medical data?”

While creating new NHS numbers is current NHS guidance for individuals updating their gender marker, this can leave information from their previous health record impractical to retrieve. ${ }^{4}$ Through making himself visible, Jack therefore faces the problem of making his health history and needs invisible-at worst they are lost, or at best harder to access for practitioners-within a medical system that is not designed for him.

Attending to the needs of all transgender people is critical to ensure we provide inclusive care.

Historically, as researcher Ruth Pearce has suggested, being trans was defined through fixed criteria devised by medical experts, and perceived as being "fixable" through transitioning. ${ }^{5}$ This conditional view of "transgender" imagines being trans as a defect that needs correcting, as opposed to the emerging view of gender as fluid and flexible, which positions trans as a social identity.

"Trans as movement" is a framework put forward by Pearce to account for a more variable and versatile experience of gender. 5 "Gender" here can be thought of as becoming, rather than as fixed or fixable points. With outdated models of gender commonly embedded into the design of healthcare organisations, this conceptual model is useful for health practitioners so that they can be more aware of the complexity of their patients' lives.

In our study we show, for instance, how trans identities can become erased in healthcare settings. ${ }^{6}$ One of our research participants, Jane, who is agender, felt ambivalent about changing the gender marker on their medical record, adding that "it depends on, like, transitioning and things like that." Inflexible medical forms, which cannot account for diverse genders, such as agender, produce hurdles for patients that need to be negotiated for access and support from healthcare services.

Ignoring the fluidity and diversity of gender can lead to serious harm for patients. A case report by Stroumsa and colleagues presented one example of a pregnant trans man attending an emergency department. ${ }^{7}$ Due to being incorrectly triaged, his medical care was delayed, resulting in his fetus dying in utero. These examples are illustrative of a gender illiteracy in mainstream healthcare that needs attending to.

Realising and responding to trans people's needs requires addressing these underlying systemic problems, which exclude trans people from existing in, and participating within, healthcare structures. Conceptual models that can account for diversity and fluidity of gender within healthcare are critical for ensuring inclusive care.

Using the "trans as movement" framework to re-think gender offers new possibilities for healthcare providers, researchers, and importantly trans people in health settings. 
This framework enables us to respond to the multiplicity of transitions-that is, the different ways that people transition-and the different experiences of trans people and their health needs.

It is an opportune moment to ask ourselves how the ways we think about gender in our own practices limits the types of care trans people receive, and makes invisible the diverse experiences our patients have. Moving beyond assumptions of gender binaries ("male"/“female") is imperative at the beginning stage of developing inclusive policies and training curricula, and can be embedded across all fields of healthcare practice.

Within healthcare consultations, this approach extends existing patient centred care approaches, which stress that it is critical each patient is considered in their own contexts. That is, thinking with a "trans as movement" framework in all of our practices ensures inclusive care. We all have a role to play in ensuring inclusive care for the people that trust us with their lives, regardless of their gender identity.

Adam Shepherd is a trans man and researcher exploring trans people's experiences in healthcare. He is currently studying Medicine at King's College London.

Benjamin Hanckel is a researcher at Western Sydney University, and holds a visiting scholar position at King's College London.

Competing interests: none declared.

Provenance and peer review: not commissioned, not peer reviewed

Patient consent: All participants consented to pseudonyms being used to preserve their anonymity

1 The role of the GP in caring for gender-questioning and transgender patients. RCGP position statement https://www.rcgp.org.uk/-/media/Files/Policy/A-Z-policy/2019/RCGP-position-statementproviding-care-for-gender-transgender-patients-june-2019.ashx?la=en

2 NHS population screening: information for trans and non-binary people. October 2021. https://www.gov.uk/government/publications/nhs-population-screening-information-for-transgender-people/nhs-population-screening-information-for-trans-people

3 Shepherd A, Hanckel B. Ontologies of transition(s) in healthcare practice: examining the lived experiences and representations of transgender adults transitioning in healthcare. Health Sociol Rev 2021;30:41-57. doi: 10.1080/14461242.2020.1854618. pmid: 33622199

4 https://pcse.england.nhs.uk/media/2892/process-for-registering-a-patient-gender-re-assignmentv10.pdf

5 Pearce R. Understanding Transhealth. Discourse, power and possibility. June 2018. Bristol University Press. https://policy.bristoluniversitypress.co.uk/understanding-trans-health

6 Shepherd A, Hanckel B. Ontologies of transition(s) in healthcare practice: examining the lived experiences and representations of transgender adults transitioning in healthcare. Health Sociol Rev 2021;30:41-57. doi: 10.1080/14461242.2020.1854618. pmid: 33622199

7 Stroumsa D, Roberts EFS, Kinnear H, Harris LH. The Power and Limits of Classification - A 32-Year-Old Man with Abdominal Pain. N Engl J Med 2019;380:1885-8.

doi: 10.1056/NEJMp1811491. pmid: 31091369 